\section{Native Woody Plant Seed Collection Guide for British Columbia}

\author{
S MiSHTU BANERJEE, \\ KIM CREASEY, AND \\ Diane Douglas GerTZEN
}

Crown Publications Inc, Victoria, British Columbia. Telephone: 250-386-4636.

146 p, paper, 2001, ISBN 0-7726-4340-7

Can\$29.95

This attractive publication contains an abundance of practical background on collecting seeds of British Columbia native woody species. A definite plus is the additional guidance on monitoring, field handling, and transportation of seed collections. The many full-color photos enhance the text, and amply illustrate the appearance of seed crops in the field. The 6 X 9 in $(15$ $\mathrm{X} 22.5 \mathrm{~cm}$ ) size and durable paper make this book easy to handle. The 2-page layout for each species is particularly convenient for field use because all the information on a species can be viewed at one time.

The book is organized into 3 major sections (background information, species-specific information, and appendices) that are conveniently indicated by printed color bars in the header of each page. The general introductory section occupies about 20 pages and is grouped under the headings of Basics, Monitoring and Forecasting, Collecting, and Field Storage and Transportation. The section on basics is clearly written and easily understandable by the lay person with little or no background in plant anatomy or botany. In general, the examples illustrating the text are well chosen to help the reader understand fairly technical material.

The main portion of the book (more than 100 pages) is devoted to detailed notes on 52 woody deciduous angiosperms displaying a range of fruit and seed characteristics. The species are contained within 16 different plant families that include maple, cashew, sunflower, barberry, birch, honeysuckle, dogwood, cypress, oleaster, heath, beech gooseberry, hydrangea, buckthorn, rose, and willow. Although the authors stated that they chose common species that had a diversity of uses and were broadly distributed in British Columbia, I found their selection criteria somewhat vague. I assume the authors probably based their selection on those species for which collection data and images were most readily available. It would be instructive to know how many species are commonly collected in British Columbia, and further, whether the authors intend to update the materials when information on more species becomes available.

The specific descriptions of each species are usefully organized into sections on crop intervals, flowering habits, forecasting, monitoring, and seed collection. The collection section is further subdivided into brief notes regarding ripe fruits and mature seeds, collection methods, and procedures for field storage and transportation. The descriptions, although fairly complete, could have been nicely rounded out with a brief section on the common uses of each species. A question that frequently arose in my mind while reading the text was, "Why would someone be interested in going to the trouble of monitoring and collecting these seeds?" Inclusion of traditional uses by native peoples also would be informative.

I especially appreciated the effort that the authors took to include the images - for every species—of the stages of flowering, forecasting, collection, and fruits (and/or seeds). Having images of all critical collection stages greatly enhances the utility of the photos. In general, the photos of larger objects such as flowers and fruits were of good quality, but the macro photos were often poor and out of focus. In a number of images, debris and extraneous material obscured the main objects of the photo.

The 20 pages of appendices contain practical information on ecological zones, seed and equipment suppliers, cutting tests, seed collection worksheets, and other useful reference material. This section begins with a 2-page map showing the distribution of major ecological zones, and the great diversity of landscapes found in British Columbia. The section on cutting tests provides clear instructions on conducting the test and also includes some photos to show what you expect to see when actually performing the tests on seed samples. Lists of suppliers and native plant societies are helpful for collectors who are just getting started, although, of course, the information eventually will become dated. Inclusion of an example of a seed collection form serves as an useful guide to novice collectors, and helps ensure that essential information about the seed collec- tion is not neglected. The list of references and the glossary provides the collector with additional material to enhance their knowledge about basic botany, plant identification, plant propagation, and seeds.

The only drawback is the poor quality of the writing, to a degree that is distracting. I found myself re-reading sentences several times in an attempt to understand what the authors were trying to say. The order within individual paragraphs was often the reverse of the logical order, that is, the specific was stated, followed by the general. Also, throughout the text, the same information was repeated in several places. An editor's hand could have considerably improved the organization and tightened up the text. A minimal amount of attention to these points would have greatly reduced the effort required by the reader.

Nonetheless, this useful volume on seed collection of British Columbia's native woody plants is well worth buying. Congratulations to the authors for their diligence in compiling this hard-to-obtain information in an approachable book.

\section{- Carole L Leadem}

Dr Leadem has been a research scientist in tree seed physiology with the British Columbia Ministry of Forests Research Branch for $24 \mathrm{y}$. She's an author of numerous publications on seed biology and an associate editor for New Forests. 